\title{
Stress path during pressuremeter test and link between shear modulus and Menard pressuremeter modulus in unsaturated fine soils
}

\author{
Vincent Savatier ${ }^{1}$, Maxime Savatier ${ }^{2}$ \\ ${ }^{1}$ EGIS Geotechnique 33-43 Avenue G. Pompidou BP 13115-31131 Balma Cedex France \\ 21 rue des remparts 31450 Montgiscard
}

\begin{abstract}
This paper presents the stress path before and during a pressumeter test using a Modified Cam-Clay model. This model have been used for unsaturated clay with continuous water phase (D2 domain according to Boutonnier 2007) and for silty to clayey soils with discontinuous water phase (D1 domain - ibid.). After reminding the stress distribution around a pressuremeter cell and the meaning of the Menard pressuremeter modulus which is linked to the soil shear modulus, we explain the stress state during pressuremeter modulus measurement. Then, we show that this stress path diagram can be used to explain classical observations made using Menard pressuremeter tests in continental area and typically:

- Measurement of high ratio "Menard pressuremeter modulus / pressuremeter limit pressure" in clay subjected to drought.

- Limit pressure and Ménard pressuremeter modulus variation with respect to drought in silty clay situated in water-table fluctuation area.

Finally, we will try to show the consequences of these stress paths for performing and interpreting pressuremeter test in unsaturated and collapsible soils.
\end{abstract}

\section{Stress state around pressiometer cell in Cambriges axes}

In the Cambridge axe $p$ is the average soil stress $p=\frac{\sigma_{1}+\sigma_{2}+\sigma_{3}}{3}$ and $q=\sigma_{1}-\sigma_{3}$.the stress deviator.

The stress state around a pressuremeter test look like the stress state around an expending cylindrical cavity. Therefore in elastic state expansion the stress path is a pure shear (isovolumetric). In figure $1, z$ is vertical axe; $K o$ the "at rest earth pressure coefficient", $h$ is test depth; $r f$ the cavity radius; $r_{o}$ the cavity radius at the pressuremeter cell introduction.; $p_{c 0}$ soil pressure at the borehole limit.

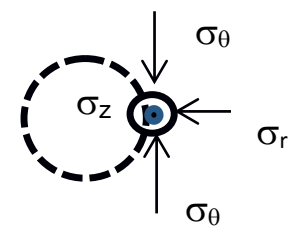

Figure 1. Stress definition around pressuremeter cell

In elastic state the stresses equations around a cylindrical hole with radius $r_{0}$ are:

$$
\begin{gathered}
\sigma_{r}=\sigma_{0}-\left(\sigma_{0}-p_{c o}\right) \frac{r_{f}^{2}}{r^{2}} \\
\sigma_{\theta}=\sigma_{0}+\left(\sigma_{0}-p_{c o}\right) \frac{r_{f}^{2}}{r^{2}} \\
\sigma_{z}=\sigma_{v} ; \text { avec } \sigma_{0}=K_{O} . \sigma_{v}
\end{gathered}
$$

- Before drilling : $\sigma_{z}=\gamma \cdot h ; \sigma_{\theta}=\sigma_{r}=K_{0} .2 h$; therefore:

$$
p i=\gamma h\left(1+2 K_{0}\right) / 3 ; q i=\gamma h \cdot\left(1-K_{0}\right)
$$

- During drilling if remaining in elastic state (this is the most frequent situation for unsaturated soil) the stress equations at the hole limit are :

$$
\begin{gathered}
\sigma_{z}=\gamma \cdot h \\
\sigma_{r}=p_{c 0 ;} \\
p=(1 / 3)\left(\sigma_{z}+\sigma_{r}+\sigma_{\theta}\right)=\gamma h\left(1+2 K_{0}\right) / 3
\end{gathered}
$$

Therefore :

$$
p=(1 / 3)\left(\gamma \cdot h+p_{c 0}+\sigma_{\theta}\right)=\gamma h\left(1+2 K_{0}\right) / 3
$$

Thus $\sigma_{\theta}=\gamma h(2 K o)-\mathrm{p}_{\mathrm{co} 0} ; q=\max \left(\sigma_{z}-\sigma_{r} ; \sigma_{r^{-}} \sigma_{\theta}\right)$.

For an empty hole that gives:

$$
q=\max \left(\gamma \cdot h ; 2\left(\gamma h\left(K_{0}\right)\right) ; p=\gamma h\left(1+2 K_{0}\right) / 3\right.
$$

- During test while staying in elastic state stress equation are the same that equations (2) replacing $\mathrm{p}_{\mathrm{c} 0}$ with $\mathrm{pc}$ pressure at the hole limit:

$$
q=\max \left(\gamma \cdot h-p_{c} ; 2\left(\gamma h\left(K_{0}\right)-p_{c}\right) .\right.
$$

In the following we will consider the most frequent case where $\gamma \cdot h-p_{c}<2\left(\gamma h\left(K_{0}\right)-p_{c}\right.$ (always observed when $K 0>0,5)$. Thus we have:

$$
q=2\left(2 h\left(K_{0}\right)-p_{c}\right) ; p=\gamma h\left(1+2 K_{0}\right) / 3
$$

The deformation of the radius $r$ follows in elastic state follows ( $\mathrm{G}$ is the shear modulus):

$$
d u=d p_{c} \cdot \frac{r o+u}{G}
$$

This could be written; ( $V o$ is initial cell volume at the contact with hole limit and $V$ is cell volume during the test): $d V=2 d p_{c} \frac{V_{0}+V}{G}$

$$
\text { that gives: } \quad G=2(V 0+V) \frac{d p}{d V}
$$

Or with Menard pressuremeter Modulus:

$$
\mathrm{E}=2(1+v) \cdot(\mathrm{V} 0+\mathrm{V}) \frac{d p}{d V}
$$

For over-consolidated soil for each average stress $p$ noted $\sigma^{\prime}$; the oedometric modulus can be defined with the following formula: 


$$
\text { Eoed }=\frac{2,3\left(1+e_{i}\right) \cdot \sigma_{1}^{\prime}}{C s}=\frac{4,6\left(1+e_{i}\right) \sigma_{m}^{\prime}}{3 \cdot C s}
$$

Cs is the $\mathrm{LOG}_{10}$ swelling index; $\sigma_{\mathrm{m}}$ the average stress which value during an oedometric test is $\sigma^{\prime}{ }_{\mathrm{m}}=2 / 3 \sigma^{\prime}{ }_{1}$. $\sigma^{\prime}{ }_{1}$ is the principal major stress.

Using the relationship between oedometric and shear modulus, the following relation between $\mathrm{G}$ and $\sigma_{\mathrm{m}}$ is obtained:

$$
G=\frac{(1-2 v)}{(1-v)} \cdot \frac{4,6\left(1+e_{i}\right) \cdot \sigma_{m}^{\prime}}{3 \cdot C s}
$$

Thus shear modulus is proportional to average stress.

- During test when plastic state is reached

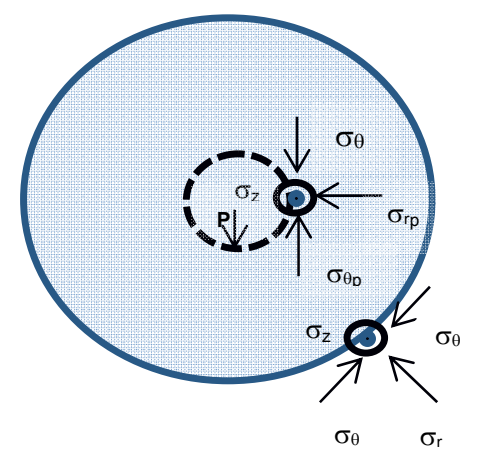

Figure 2.Plastic stress definition around pressuremeter cell

It appears around the cell a soil crown in which limits the values of $p$ and $q$, can be found with:

- The equation of the limit line for normally consolidated soil with hydric state that allows consolidation:

$$
q=\left(\sigma_{r p}^{\prime}-\sigma_{\theta p}^{\prime}\right)=M \sigma_{m}^{\prime}=M \cdot p^{\prime}
$$

- The equation of the yeld flow surface for overconsolidated clay that do not allows consolidation:

$$
q^{\prime 2}-M^{2} p^{\prime}\left(\sigma_{m p o}^{\prime}-p\right)=0
$$

$$
\begin{array}{r}
\text { with } M=\frac{6 \sin \phi^{\prime}}{3-\sin \phi^{\prime}} \text {. Therefore: } \\
\left(\sigma_{\text {rp }}^{\prime}-\sigma^{\prime}{ }_{\theta_{p}}\right)^{2}-M^{2} \sigma_{m}^{\prime}\left(\sigma_{m p 0}^{\prime}-\sigma_{m}^{\prime}\right)=0
\end{array}
$$

- $\sigma_{\text {mpo }}^{\prime}$ is the isotropic pre-consolidation stress

- $\phi$ ' soil effective angle of internal friction

According to Wood (1990) ref [1], when consolidation yield flow surface (equation (9)) is reached; the effective stress follows the equation:

$$
\frac{p^{\prime} i}{p^{\prime}}=\left\{\frac{M^{2}+\left(\frac{q}{p^{\prime}}\right)^{2}}{M^{2}+\left(\frac{q i}{p^{\prime} i}\right)^{2}}\right\}^{\wedge}
$$

with $\mathrm{M}$ as above $; \Lambda=\frac{\lambda-\kappa}{\lambda}=\frac{C c-C s}{C s}$;

$\mathrm{Cc}$ is the $\mathrm{LOG}_{10}$ compression index; $\lambda$ the compression index; $\kappa$ the swelling index; $p i$ and $q i$ are the initial values of $p$ et $q$ before putting the cell in the borehole.

We will call:

$$
\mathrm{STi}=\left[M^{2}+\left(\frac{q i}{p^{\prime} i}\right)^{2}\right] p i^{\frac{1}{\Lambda}}=\left[M^{2}+\left(\frac{3(1-K o)}{1+2 K o}\right)^{2}\right] p i^{\frac{1}{\Lambda}}
$$

By deriving equation (11) it can be shown that:

$$
d p^{\prime}=\left\{\frac{2 \cdot q \cdot d q}{\text { STi. }\left(\frac{\lambda-2 \kappa}{\lambda-\kappa}\right)\left(\frac{1}{p^{\prime}}\right)^{\frac{3 \kappa}{\lambda-\kappa}}-2 M^{2} p^{\prime}}\right\}
$$

At the outside limit of this crown, the soil follows equation [1].

According to D. Rangeard ref [2] for a clayey saturated soil case (with permeability below $10^{-6} \mathrm{~m} / \mathrm{s}$ ) the pressuremeter test is fast enough to have isovolumetric plastic deformations. Thus the following stress paths are obtained. They are given considering two cases:

- If $\sigma_{m p o}^{\prime}>p=\gamma h\left(1+2 K_{0}\right) / 3$ deformation will be with effective stress increase and negative interstitial water pressure $(\mathrm{U}<0)$

- If $\sigma_{m p o}^{\prime}<p=\gamma h\left(1+2 K_{0}\right) / 3$ deformation will be with effective stress decrease and positive interstitial water pressure $(\mathrm{U}>0)$

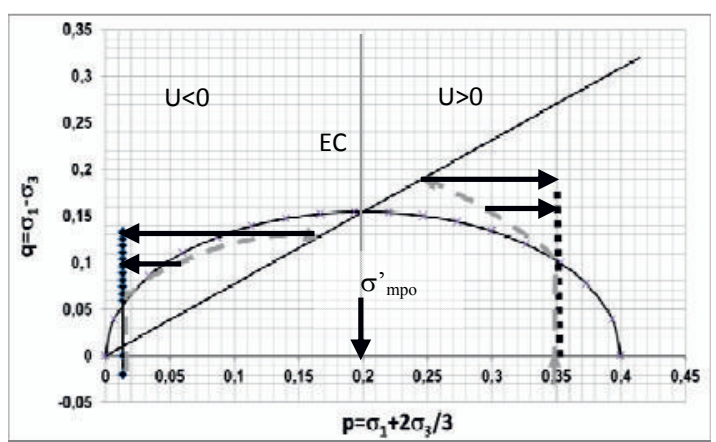

Figure 3. Stress way in a saturated clay( effective stresses paths are in grey with dotted line and total stresses paths are in black).

\section{Pressuremeter behavior of unsaturated soils}




\subsection{Saturations variation}

We will consider two of the unsaturated soil states defined by Boutonnier [2007] ref [3] :

- D1: for this state the gas phase is continuous (suction is over air-entry suction $\mathrm{s}_{\text {air }}\left(\mathrm{s}>\mathrm{s}_{\text {air }}\right)$ and saturation degree is over air entry saturation $\mathrm{S}_{\text {lair }}$ (usually between 0,7 to 0,8 ).Additionally suction has no effect on volumetric forces and his variation effect is limited to inter-grain forces.

- D2 : for this state, the gas phase is discontinuous and subdivided in bubbles in contact with several soil grains. Suction is under Sair and saturation is $\mathrm{Sr}$ with $\mathrm{S}_{\text {lair }}<\mathrm{Sr}<\mathrm{Sle}$. Sle is the shrinkage limit.

The water content is $\mathrm{W}=\frac{P_{w}}{F q}$; with $\mathrm{PW}$ water weight; Ps solid part of soil weight. Considering a soil change from a state $i$ to a state $f$, we have the following properties:

$$
\begin{gathered}
\mathrm{W}_{\mathrm{i}}=\frac{P w_{i}}{P S}=\frac{V w_{i}}{V v_{i}} \cdot \frac{V v_{i}}{V s} \cdot \frac{2 w}{\gamma s}=\mathrm{S}_{\mathrm{li}} * \mathrm{e}_{\mathrm{i}} \frac{\gamma w}{\gamma s} \\
\mathrm{~W}_{\mathrm{f}}=\mathrm{S}_{\mathrm{lf}} * \mathrm{e}_{\mathrm{f}} \frac{\gamma w}{\gamma s}
\end{gathered}
$$

$V w_{\mathrm{i}}$ is initial water volume, $V s$ solid grain volume; $e_{i}$ et $e_{f}$ are respectively the initial and final void ratio

During a pressuremeter test, deformation will be with constant water content for both D1 and D2 states: In $\mathrm{D} 1$ soil because of the water discontinuity; in $\mathrm{D} 2$ soil because of the relative high velocity of the test compared with water pressure dissipation. According that: $W i=W f$ that gives: $\quad S_{l i} * e_{i} \frac{\gamma w}{\gamma s}=S_{l f} * e_{f} \frac{\gamma w}{\gamma s}$

With $S l_{i}$ et $S l_{f}$ initial and final liquid saturation.

Therefore : $S l_{i} * e_{i}=S l_{f} * e_{f}$

Volumetric deformation between start and end of deformation is :

$\varepsilon_{V}=\frac{e_{f-} e_{i}}{1+e_{i}}=\frac{\frac{S_{l_{i}}}{S_{l_{f}}} e i-e i}{1+e i}=\frac{e_{i}}{1+e_{i}}\left(\frac{S_{l_{i}}}{S_{l f}}-1\right)$

thus :

$$
S l_{f}=\frac{S_{l i}}{1+\left(\frac{1+e i}{e i}\right) \varepsilon_{V}}
$$

We will consider a deformation that leads from a stress $p^{\prime}{ }_{i}$ to a stress $p_{f}^{\prime}$. Beyond this point, we will note them respectively $\sigma_{m i}^{\prime}$ et $\sigma_{m f}^{\prime}$ to avoid confusion with pressuremeter cavity pressure. During this deformation:

- For over-consolidated soil :

$$
\varepsilon=-\kappa \cdot \ln \left(\frac{p_{f}^{\prime}}{p_{i}^{\prime}}\right)=-\frac{C s}{\left(1+e_{i}\right)} \log \left(\frac{\sigma_{m_{f}}^{\prime}}{\sigma_{m_{i}}^{\prime}}\right)
$$

From (13) and (14), the evolution of saturation during a pressuremeter deformation is:

$$
S_{l f}=\frac{S_{l i} \cdot e i}{e i+\left(-C s \cdot \log \left(\frac{\sigma_{m f}^{\prime}}{\sigma_{m i}^{\prime}}\right)\right)}
$$

- For normally consolidated soil:

$$
\varepsilon=-\lambda \cdot \ln \left(\frac{p_{f}^{\prime}}{p_{i}^{\prime}}\right)=-\frac{C c}{\left(1+e_{i}\right)} \log \left(\frac{\sigma_{m_{f}}^{\prime}}{\sigma_{m_{i}}^{\prime}}\right)
$$

From (13) and (16) the evolution of saturation during a pressuremeter deformation is in this case:

$$
S_{l f}=\frac{S_{l i} \cdot e i}{e i+\left(-C c \cdot \log \left(\frac{\sigma_{m f}^{\prime}}{\sigma_{m i}^{\prime}}\right)\right)}
$$

\subsection{Relationship between total stress and effective stress for D1 or D2 soil states}

According to its definition, the variations of the effective stress follow the relationship:

$$
d \sigma_{m}^{\prime}=d \sigma_{m-}\left(1-S_{l}\right) d P_{g}-S_{l} d P l
$$

$S l$ :liquid saturation ; $d P g$ : gas pressure variation ; $d P l$ : liquid pressure variation

\subsubsection{D1 soil case}

In D1 case the total stress variation will be applied directly on the hydric bridges between the soil grains and gas pressure will not change. Otherwise, liquid pressure variation $d P l$ in hydric bridges, will be proportional to the effective stress variation. The proportionality ratio Ksg will depend of grain surface state and will be above or equal to one. Thus we have the following relationship :

$$
d \sigma^{\prime} m=K_{s g} d P l
$$

Equation (18) gives then $\mathrm{d} \sigma_{\mathrm{m}}^{\prime}=-\mathrm{d} \sigma_{\mathrm{m}}-\mathrm{K}_{\mathrm{sg}} S_{/} \mathrm{d} \sigma_{\mathrm{m}}^{\prime}$ and then:

$$
d \sigma_{m}=\left(1+K_{s g} S_{l}\right) d \sigma_{m}^{\prime}
$$

\subsubsection{D2 soil case}

In $\mathrm{D} 2$ case, the gas phase is discontinuous and divided in bubbles in contact with several soil grains. Since gas has a higher deformability than liquid, it will absorb most of the deformation and liquid pressure will stay already constant.

Gas pressure Pg will follows Mariotte et Henry laws. This gives:

$$
\text { Pg. } V g+H(t) d P g=P g o V o
$$


- Pgo and Pg: gas pressure respectively before and after deformation

- $\quad V g$ et $V g o:$ gas volume before and after deformation

- $H(t)$ Henry constant that gives dissolved gas quantity variation according to gas pressure variation and time.

$$
H(t=0)=0 ; H(t=\infty)=0,02(T / T o)
$$

$T=$ temperature in $\mathrm{K} ; T 0=293^{\circ} \mathrm{K}$

As pressuremeter test is fast, dissolved gas concentration has no time to change and (22) can be simplified as :

$$
\text { Pg.Vg+Pgo.Vgo }
$$

According to the saturation degree definition (23) :

$$
\text { Pg. }(1-\mathrm{Sl})=\text { Pgo. }(1-\mathrm{Slo})
$$

And then $P g=P g o \frac{1-S l_{o}}{1-S l_{i}}$ that gives by derivation:

$$
d P g=-P g o(1-S L o) \cdot \frac{d S l}{(1-S l)^{2}}
$$

As $d P l=0$ equation (18) gives: $d \sigma_{m}^{\prime}=d \sigma_{m}-\left(1-S_{l}\right) d P_{g}-S_{l}$ and then:

$$
\begin{gathered}
d P l=d \sigma_{m}+\operatorname{Pgo}(1-S L o) .\left(1-S_{l}\right) \frac{d S l}{(1-S l)^{2}} \\
d \sigma_{m}=d \sigma_{m^{-}}^{\prime} \operatorname{Pgo}(1-S L o) \cdot \frac{d S l}{(1-S l)} \cdot
\end{gathered}
$$

\subsection{Plastic stress variation around pressiometer}

The following figure provides the stress distribution in a thin crown of soil around a pressiometric cell that has reached the plastic state.

The increase of P2 the pressure in this cell drives the soil from a state $\mathrm{n}$ to a state $\mathrm{n}+1$.

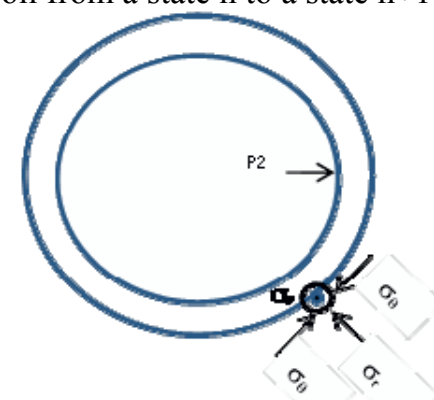

Figure 4. Stress distribution around a pressiométrique cell

We will assume that the thickness of the crown is thin enough to have constant shear strength in all its area between $\mathrm{P} 2$ to $\mathrm{P} 2+\mathrm{dP} 2$. In these conditions:

$$
\sigma_{\mathrm{r}}-\sigma_{\theta}=2(\mathrm{P} 2-\mathrm{Po})=2 \mathrm{Su}
$$

Su : undrained shear strength

Po : soil pressure before the test.
The notations, for the transformation from $n$ to $n+1$ state, are the following:

\begin{tabular}{|lll|}
\hline state $\mathbf{n}$ & gives & state $\mathbf{n}+\mathbf{1}$ \\
$P 2$ & gives & $P 2+d P 2$ \\
$2 \tau_{n}=\sigma_{r}-\sigma \theta=2(P 2-P o)$ & gives & $2 \tau_{n+1}=2(P 2-P o)+2 d P 2$ \\
& & \\
$\sigma^{\prime} \mathrm{m}_{\mathrm{n}}$ & gives & $\sigma^{\prime} m_{n+1}=\sigma m+d \sigma^{\prime} m$ \\
$\sigma \mathrm{m}_{\mathrm{n}}$ & gives & $\sigma m_{n+1}=\sigma m+d \sigma m$ \\
\hline
\end{tabular}

- The application of equation (8) between $n$ and $n+1$ in a normally consolidated soil (likes collapsible loess) gives:

$$
\sigma^{\prime} m_{n+1}=\sigma^{\prime} m_{n}+2 M d P 2
$$

- Considering that $q==\sigma_{r^{-}} \sigma_{\theta}=2(P 2-P o) ; d q=2 d P 2$, and $p^{\prime}=\sigma^{\prime} m_{n}$, the application of the equation (12) for an over consolidated soil gives:

$$
d \sigma^{\prime} m=\left\{\frac{2 \cdot q \cdot d q}{\operatorname{STi} \cdot\left(\frac{\lambda-2 \kappa}{\lambda-\kappa}\right)\left(\frac{1}{p^{\prime}}\right)^{\frac{3 \kappa}{\lambda-\kappa}}-2 M^{2} p^{\prime}}\right\}
$$

Note that all the elementary crowns that are in plastic state will be on the plastic deformation curve and follows from $n$ to $n+1$ states, equation (28) for loessic soil and equation (29) for overconsolidated clay.

Thus, the particular crown situated at the cell contact will follows equation (28) to (29) for each soil type.

\section{Stress way of pressuremeter test in unsaturated soil}

\subsection{Unsaturated clay}

The soil will be in D2 state and follows modified cam clay model. Thus on elastic state the crown of soil around the pressuremeter cell will follows an isovolumetric shear. The effective stress $\sigma^{\prime} m$ will be above total stress, with a constant difference to so the initial suction. $\sigma^{\prime} m=p^{\prime}$ follows the equation:

$$
q^{\prime}=q ; \quad p^{\prime}=p+S_{0}=p+\left(u_{a}-u_{w}\right)
$$

with: $u_{a}$ air pressure; $u_{w}$ water pressure .

Saturation degree $S_{0}$ will stay constant.

Shear modulus will be proportional to $\sigma_{\mathrm{m}}=p$ ' according to equation (7).

We remind that the pressuremeter modulus will follow:

$$
E m=(1+v)\left[\frac{(1-2 v)}{(1-v)} \frac{4,6\left(1+e_{i}\right)\left(\sigma_{m}+s o\right)}{3 C s}\right]
$$


Therefore an increase of suction; will increase pressuremeter modulus.

In the plastic state, for each increase of stress path in the crown of soil around the pressuremeter :

- $\quad$ Saturation degree will follows equation (17)

- Effective variation $d \sigma m=\sigma m_{n+1}-\sigma m_{n}$ will follows equation (29) that will allow effective stress calculation step by step.

- $\quad \sigma m_{\mathrm{n}}$ calculation from $\sigma^{\prime} m_{n}$ will be done by equation (26)

The following figures give the stress path for a less overconsolidated clay with high suction (fig 5); and for a very overconsolidated clay with a low suction (fig 6).

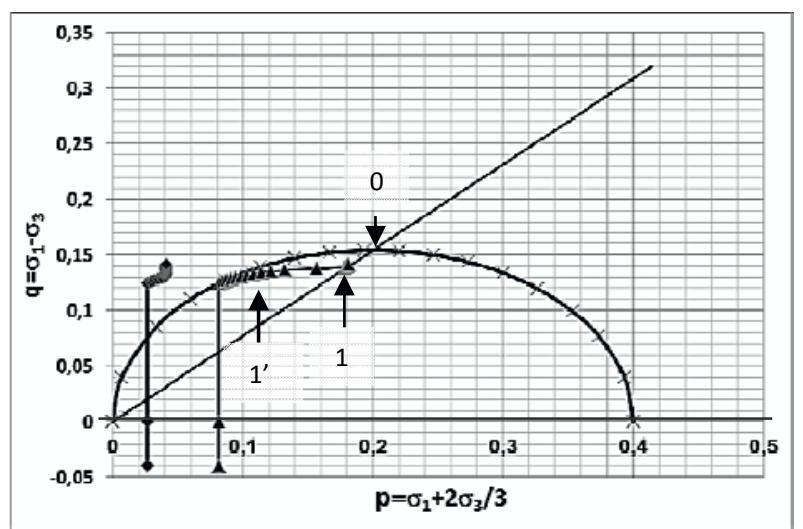

Figure 5. Pressuremeter Stress path in unsaturated clay with low suction compared with $\sigma$ 'p

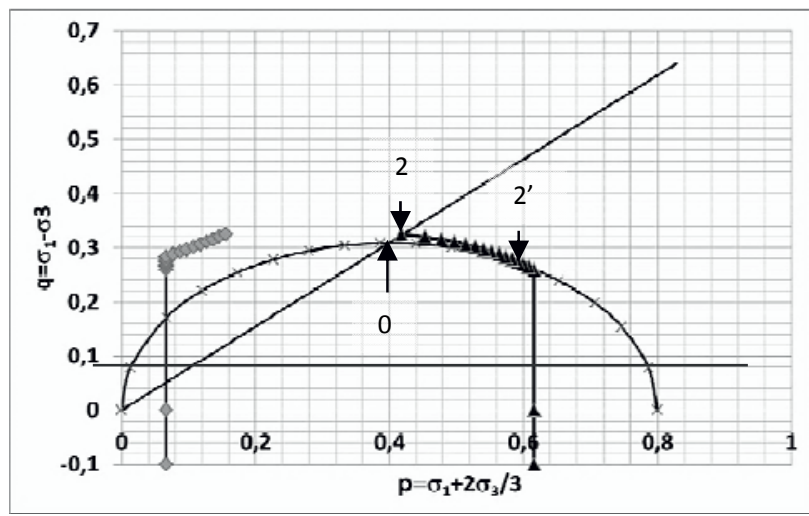

Figure 6. Pressuremeter stress path in unsaturated clay with high suction compared with $\sigma_{p}^{\prime}$

Depending on initial saturation $S o$, initial suction $s_{o}$ and soil deformability, the crown at cell contact will reach the critical point (point 1 or 2 on figures) or will stop before (point 1'or 2' on figures).

It results from the figures 4 and 5 that $q=\sigma_{r^{-}}^{\prime} \sigma^{\prime}{ }_{\theta}$ and therefore the limit pressure value will be similar to the limit pressure in a saturated soil with the same $\sigma^{\prime} p$. Consequently, an increase of suction due to dryness will increase the $E \mathrm{Em} / \mathrm{pl}$ *ratio proportionally to $\sigma m+s o$ and when wet weather decrease suction $E m / p l^{*}$ ratio will also decrease in the same way. This is an explanation of the experimental observation of high rapport $E m / p l^{*}$ in clayey sol between 0 to $3 \mathrm{~m}$ depth during dry periods.

The existence of different path of stress depending on initial saturation suction and total stress shows that interpretation of pressuremeter test using finite elements calculation based on saturated Cam clay model may fail because of these parameters influence.

\subsection{Unsaturated silts collapsible soil}

Soil state will be D1 and he follows a pure friction law or a normally consolidated law with consolidation during deformation.

On the elastic crown, as in clayey soil, shear will be iso-volumetric with an effective stress linked with total stress by the same formula: $q^{\prime}=q ; p^{\prime}=p+s o$. Note that $s_{o}$ is here a function of saturation degree So and will stay constant during elastic step in this case too. Therefore, pressuremeter modulus will increase with suction increase in the same way than in clayey soil .

On the plastic crown, for each loading path:

- $\quad$ Saturation degree will follows equation (17)

- Effective variation $d \sigma_{m}^{\prime}=\sigma^{\prime} m_{n+1}-\sigma^{\prime} m_{n}$ will follows equation (28). This will allows the calculation of effective stress step by step.

- $\quad \sigma m_{n}$ calculation from $\sigma m_{n}$ will be done by using equation (20) as long as saturation will be below a limit saturation $\mathrm{S}_{\mathrm{lim}}$, which is linked to a limit suction. Over this value, soil will pass in D2 state and follows equation (26).

The following figures gives the stress path for a collapsible soil with initial saturation $S=50 \%$ and initial average stress of $66 \mathrm{kPa}$ with an initial suction of 150 $\mathrm{kPa}$ (fig 7) and with a higher initial suction of $350 \mathrm{kPa}$ (fig 8).

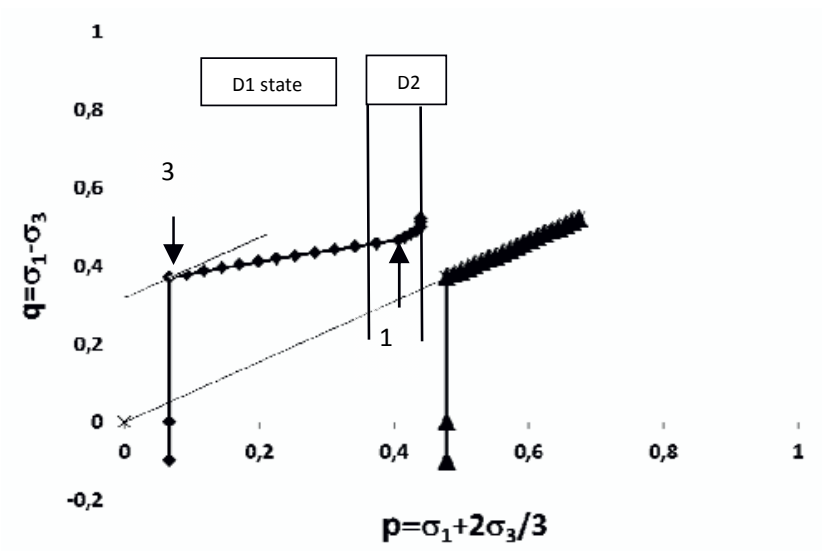

Figure 7. Pressuremeter stress path in unsaturated collapsible loess with low suction

aVincent.savatier@egis.fr 


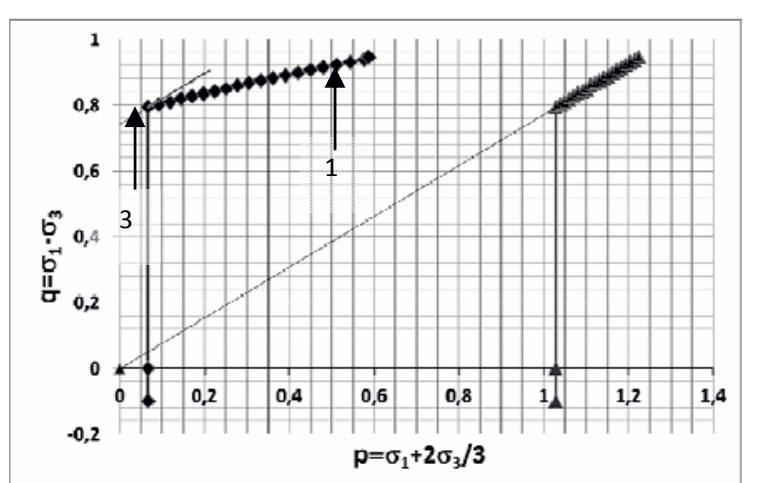

Figure 8. Pressuremeter stress path in unsaturated collapsible loess with high suction

It appears that pressuremeter modulus Em will increase proportionally to the amount of average initial total stress with suction $\sigma_{\mathrm{mo}}+s_{o}$ while $\mathrm{q}=\sigma_{\mathrm{r}}{ }^{-} \sigma^{\prime}{ }_{\theta}$ will increase proportionally to $M\left(\sigma_{\mathrm{mo}}+s_{o}\right)$. Thus $E m / p f^{*}$ ratio $\left(p f^{*}\right.$ corresponding to point 3 on the figures) will be constant. For limit pressure (point 1 on the figures 7 and 8) the stress path will depend on initial saturation degree and suction.

For low saturations, soil will stay in D1 state and $E \mathrm{~m} / \mathrm{pl}^{*}$ ratio will stay constant with suction variation. The $E M / p l^{*}$ ratio will depend, in this case, on compressibility coefficient $\mathrm{Cc}$ and on initial saturation So.

For higher saturation, $E m / p l *$ variation will depend on initial suction. Over a limit value of initial suction, soil will also stay in D1 state with a constant $E M / p l^{*}$ ratio. Below this limit value, a part of the plastic crown will pass in D2 or D3 state. In that case, soil consolidation will not be possible during the test and $p l^{*}$ increase with suction will not continue to be linear. $\mathrm{Em} / \mathrm{pl}$ * ratio will therefore increase with suction.

This helps to explain the pressuremeter modulus and limit pressure variations in silt in the vadose area. In the case of water table level increase, soil suction will decrease or disappear, leading to a high decrease of pressuremeter modulus and limit pressure (divided by two for the study case of the figures 7 and 8). On the contrary, a water level decrease and a growing of evapotranspiration will increase suction and therefore limit pressure and modulus with a $E \mathrm{~m} / \mathrm{pl}$ * ratio constant or slightly growing.

Note also that as seen above, for the clayey soil, the stress paths depend on initial suction and saturation. Therefore, estimation for soil of effective friction ratio or of shear strength using finite elements models based on pure friction soil model may also fail if suction and saturation incidence is not low.

\section{Conclusion}

The estimation of saturation and suction variations in unsaturated soil around a pressuremeter cell allows drawing qualitatively the stress path during a pressuremeter test in clayey and collapsible loessic soils. It shows that stresses path are depending on initial saturation degree and suction. This must lead to be very careful when using finite elements calculation with saturated model or pure friction model in order to estimate cam clay soil parameter or modulus, friction angle and dilatancy estimation. It seems necessary to check that the soil is perfectly saturated or perfectly dry to avoid calculation disturbance due to saturation and suction variation.

Onshore, in the very frequent case of unsaturated soil, these methods will need to take into account the effect of initial saturation and suction.

This could be done by using the presented method or similar. For this purpose, it will be necessary to sample soil for each pressuremeter test in order to measure in situ suction and saturation. This may be done by using a core cutter sampler in order to do the test cavity excavation and the soil sampling at the same time.

\section{References}

1. Y. Bentaiebi ; thèse Dep. Génie Civil Géol. et Mine Ecole polytechnique de Montréal (2011)

2. D. Rengeard; thèse école centrale de Nantes; www.theses.fr/2002NANT2092; 37- 57 (2002)

3. L. Boutonnier; Comport. hydromécanique des sols fins proche de la saturation thèse de docteur de l'INP de Grenoble 95-100 (2007)

4. V.Savatier; P. Garnier; JNGG 2014 Sols effondrables interprétation théorique et amélioration de l'essai double œdomètre Roumain 108 (2014) 